\title{
Constant Turnover of Arachidonic Acid and Inhibition of a Potassium Current in Aplysia Giant Neurons
}

\author{
Robert O. Carlson* and Irwin B. Levitan \\ Graduate Department of Biochemistry, Brandeis University, Waltham, Massachusetts 02254
}

\begin{abstract}
Summary. Steady-state currents at hyperpolarized membrane potentials were studied in the homologous giant neurons, LP1 and R2, of Aplysia using two-electrode voltage clamp. Nearly half of the steady-state current at voltages more hyperpolarized than $-70 \mathrm{mV}$ had characteristics similar to the inwardly rectifying potassium current $\left(I_{R}\right)$ described previously in Aplysia neurons. The pharmacological agents 4-bromophenacylbromide, indomethacin, and the phorbol ester, 12-O-tetradecanoyl-phorbol-13-acetate were found to modulate $I_{R} . I_{R}$ was stimulated with BPB and indomethacin and inhibited with TPA. These agents altered $I_{R}$ by a mechanism independent of $c$ AMP, which can also modulate $I_{R}$. The effects of these modulators are consistent with their actions on arachidonic acid (AA) metabolism in Aplysia nervous system, suggesting AA may constitutively inhibit $I_{R}$. When ganglia were perfused for $12 \mathrm{hr}$ with medium containing BSA to absorb extracellular fatty acids, $I_{R}$ was increased nearly twofold. This increase was partially inhibited by addition of AA to the perfusion medium, and completely inhibited by pretreatment of ganglia with BPB. Although no direct effect of shortterm exposure to exogenous AA was observed, long term exposure to exogenous $A A$ and several other unsaturated fatty acids was accompanied by a decrease in $I_{R}$.
\end{abstract}

Key Words arachidonic acid $\cdot$ eicosanoids $\cdot$ Aplysia $\cdot$ inward rectifier $\cdot$ phorbol ester $\cdot$ potassium current $\cdot$ protein kinase $C$

\section{Introduction}

Arachidonic acid and its metabolites, or eicosanoids, have been shown to be involved in regulation of secretory processes. The role of eicosanoids in stimulus-secretion coupling in the anterior pituitary is one of the best characterized systems. Lipoxygenase and epoxygenase products have been implicated in the mediation of hormone-induced release of the pituitary hormones adrenocorticotropin hormone $[1,40,43], \beta$-endorphin $[3,45]$, prolactin $[8$, $29,43]$, luteinizing hormone $[15,16,28,43]$, and

* Present address: The University of Michigan, Neuroscience Building, 1103 East Huron Rd., Ann Arbor, MI 48109. growth hormone $[12,13,27,43,58]$. The first direct demonstration that eicosanoids may regulate secretion through modulation of electrical activity came from work with identified neurons of the marine snail, Aplysia. At an identified synapse in Aplysia, eicosanoids have been implicated in the activation of a potassium current (S-current), which leads to inhibition of electrically-evoked transmitter release, or presynaptic inhibition [47, 48]. Modulation of potassium currents can alter cell excitability and thereby indirectly modulate neurotransmission or other secretory processes. Recently, several additional examples of AA- and eicosanoid-mediated modulation of potassium currents have been reported. Kim et al. [31] and Kurachi et al. [36] have implicated lipoxygenase metabolites in the regulation of muscarinic receptor-linked potassium channels. Also, $\mathrm{AA}^{1}$ and other unsaturated fatty acids have been shown to directly activate potassium channels in ripped-off patches from heart [30] and smooth muscle cells [46].

In the accompanying paper [11], we demonstrated constant turnover of intracellular free AA in Aplysia ganglia. This turnover was accompanied by a constant and substantial release of free AA and eicosanoids to the extracellular medium. In this paper, we report our investigation of AA-mediated regulation of an inwardly rectifying potassium current in the giant neurons, LP1 and R2, of Aplysia. This current has previously been shown to be activated by serotonin $[2,6,19]$ and Aplysia egg-laying hormone [39], through the cAMP cascade. We

1 Abbreviations: AA, arachidonic acid; AA-CoA, arachidonyl coenzyme A; TPA, 12-O-tetradecanoylphorbol 13-acetate; $\mathrm{BPB}$, 4-bromophenacylbromide; $\mathrm{PLA}_{2}$, phospholipase $\mathrm{A}_{2}$; NDGA, nordihydroguaiaritic acid; $5 \mathrm{HT}$, serotonin creatine sulfate; IBMX, isobutylmethylxanthine; DMSO, dimethylsulfoxide; $I_{R}$, inwardly rectifying potassium current. 
show now, using the pharmacological agents described in the accompanying paper and techniques which alter the amount of AA in lipid storage, that AA can also modulate $I_{R}$, independent of $c$ AMP.

\section{Materials and Methods}

\section{ELECTROPHYSIOLOGY}

Adult Aplysia californica (100 to $250 \mathrm{~g}$ ) were supplied by Alacrity Marine Biological Services (Redondo Beach, CA). To anesthetize prior to dissection, Aplysia were injected with up to $100 \mathrm{ml}$ of $0.4 \mathrm{M} \mathrm{MgCl}_{2}$. Ganglia were removed and immediately placed in artificial seawater (ASW (control), in mM: $460 \mathrm{NaCl}, 55$ $\mathrm{MgCl}_{2}, 11 \mathrm{CaCl}_{2}, 10 \mathrm{KCl}, 10 \mathrm{NaHEPES}, \mathrm{pH} 7.3$ ) with $1 \%$ (wt/ vol) glucose.

Ganglia were incubated in $1 \%$ (wt/vol) dispase in ASW for 1 $\mathrm{hr}$ at room temperature to loosen the connective tissue sheath prior to desheathing. Dispase was washed away and the abdominal or left pleural and connected left pedal ganglion, or "pleuropedal" ganglion, was pinned into a $0.5-\mathrm{ml}$ chamber of Sylgard in a plastic petri dish. The ganglion was desheathed and placed under perfusion with ASW at about $1 \mathrm{ml} / \mathrm{min}$. Perfusion was used to supply all pharmacological agents to the ganglion. DMSO was used to solubilize all agents used (except 5HT) prior to addition to ASW. The final concentration of DMSO in ASW was normally $0.05 \%$ (vol/vol), but as much as $0.25 \%$ DMSO was used to solubilize the highest concentrations of indomethacin tested. No discernible electrophysiological effects were observed for control solutions containing up to $0.25 \%$ DMSO.

The giant neuron ( 2 in the abdominal ganglion or LP1 in the pleural ganglion) was impaled with two glass microelectrodes (1-4 $\mathrm{M} \Omega$, filled with $0.5 \mathrm{M} \mathrm{K}_{2} \mathrm{SO}_{4}$ ) for intracellular recording and two-electrode voltage clamp. Two-electrode voltage clamp was performed with an Almost Perfect Electronics Voltage Clamp, a high-voltage Almost Perfect Electronics preamp (for current injection) and a W-P Instruments preamp (for monitoring voltage). Data were recorded on a Gould chart recorder and a four-channel Hewlett-Packard tape recorder for subsequent analysis. The giant neurons were clamped at -70 or $-50 \mathrm{mV}$. Pulses from this holding potential to command potentials were used to generate current-voltage $(I-V)$ curves. For command potentials more hyperpolarized than $-30 \mathrm{mV}$, these pulses were normally 0.5 to 1 $\mathrm{sec}$ in duration. The current magnitude was measured at the end of the pulse and graphed as a function of command potential.

For experiments involving perfusion or dialysis and subsequent electrophysiological measurements over extended periods of time, aseptic cell culture techniques were employed. Ganglia were washed with several changes of sterile ASW, followed by incubation in a filter-sterilized solution of $1 \%(\mathrm{wt} / \mathrm{vol})$ dispase in ASW for $2 \mathrm{hr}$. For extended perfusion, the sterile, dispasetreated abdominal and/or left pleuropedal ganglia, in groups of four to eight, were pinned to sterilized Sylgard-lined plastic 60$\mathrm{cm}$ petri dishes, and desheathed using sterile instruments. The plate was then placed under perfusion with sterile, control ASW. The giant neurons were successively placed under voltage clamp, and the resting steady-state $I-V$ curves were measured. The plate was then placed under perfusion $(-1 \mathrm{ml} / \mathrm{min})$ for $12 \mathrm{hr}$ with perfusion medium: sterile, dilute L15 (a nutrient medium from Flow Laboratories (McLean, VA); present at $20 \%$ of normal concentration) in ASW in penicillin $(10 \mathrm{IU} / \mathrm{ml})$, streptomycin
$(10 \mu \mathrm{g} / \mathrm{ml}$ ), fungizone (amphotericin B, $0.5 \mu \mathrm{g} / \mathrm{ml}$ ) and $1 \%$ (wt) vol) glucose. (Antibiotics were from Flow Laboratories.) This perfusion was carried out in a laminar flow hood. Then the plate was again placed under perfusion with control ASW, and the giant neuron steady-state $I-V$ curves were measured.

For dialysis, the dispase-treated abdominal and/or left pleuropedal ganglia (with sheaths intact), in groups of four to eight, were placed in sterile dialysis tubing (Spectro/Por $7,25 \mathrm{~K}$ molecular weight cut-off) filled with sterile, control ASW. The ganglia were then dialyzed in $250-300 \mathrm{ml}$ of medium identical to that used for extended perfusion. Dialysis was carried out in a stirred bath at $10^{\circ} \mathrm{C}$, and the dialysis medium was changed every $24 \mathrm{hr}$. The ganglia were then removed from the dialysis tubing, and each group was pinned to a $60-\mathrm{cm}$, Sylgard-lined, plastic petri dish, and the ganglia were desheathed. The plate was then placed under perfusion with control ASW and the giant neuron steady-state $I-V$ curves were measured.

All reagents were of highest grade available. 12-O-tetradecanoylphorbol-13-acetate, indomethacin, 4-bromo-phenacylbromide, nordihydroguaiaritic acid, acetylsalicylic acid, serotonin creatine sulfate and isobutylmethylxanthine were from Sigma. Forskolin was from Calbiochem. DMSO was from Aldrich. Dispase was from Boehringer-Mannheim. Inorganic salts were from Fisher. Fatty acids were from Cayman Chemicals (Ann Arbor, MI).

\section{BIOCHEMISTRY}

Methods for analyzing AA metabolism are described in the accompanying paper [11].

\section{Results}

\section{Giant Neurons Contain Inwardly Rectifying Potassium Current}

Current-voltage curves in the giant neurons, $\mathrm{R} 2$ and LP1, of Aplysia were generated with $0.5-\mathrm{sec}$ voltage steps from a holding potential of -70 to $-50 \mathrm{mV}$, to command potentials from -110 to $-40 \mathrm{mV}$. At rest, the $I-V$ curves exhibited an inwardly rectifying current at potentials more hyperpolarized than -70 $\mathrm{mV}$, which is the potassium equilibrium potential $\left(E_{\mathrm{K}}\right)$ in Aplysia neurons in ASW (see I-V curves in control ASW in Fig. 1). This inwardly rectifying current was abolished in the presence of 0.5 to $1 \mathrm{~mm}$ $\mathrm{Ba}^{2+}$ (Fig. 1). Also, lowering the potassium concentration from $10 \mathrm{~mm}$ to $2 \mathrm{~mm}$ removed the rectifying component of the current (Fig. 1). These results suggest this conductance is likely an inwardly rectifying potassium current $\left(I_{R}\right)$ of the type described previously in Aplysia neurons $[6,22] . I_{R}$ is blocked selectively by a low concentration of $\mathrm{Ba}^{2+}$, and is known to rectify inwardly at $E_{\mathrm{K}}[6,23,38]$.

We therefore defined $I_{R}$ in giant neurons as the current present at potentials more hyperpolarized than $-70 \mathrm{mV}$ that was blocked with 0.5-1 $\mathrm{mM} \mathrm{Ba}^{2+}$. 

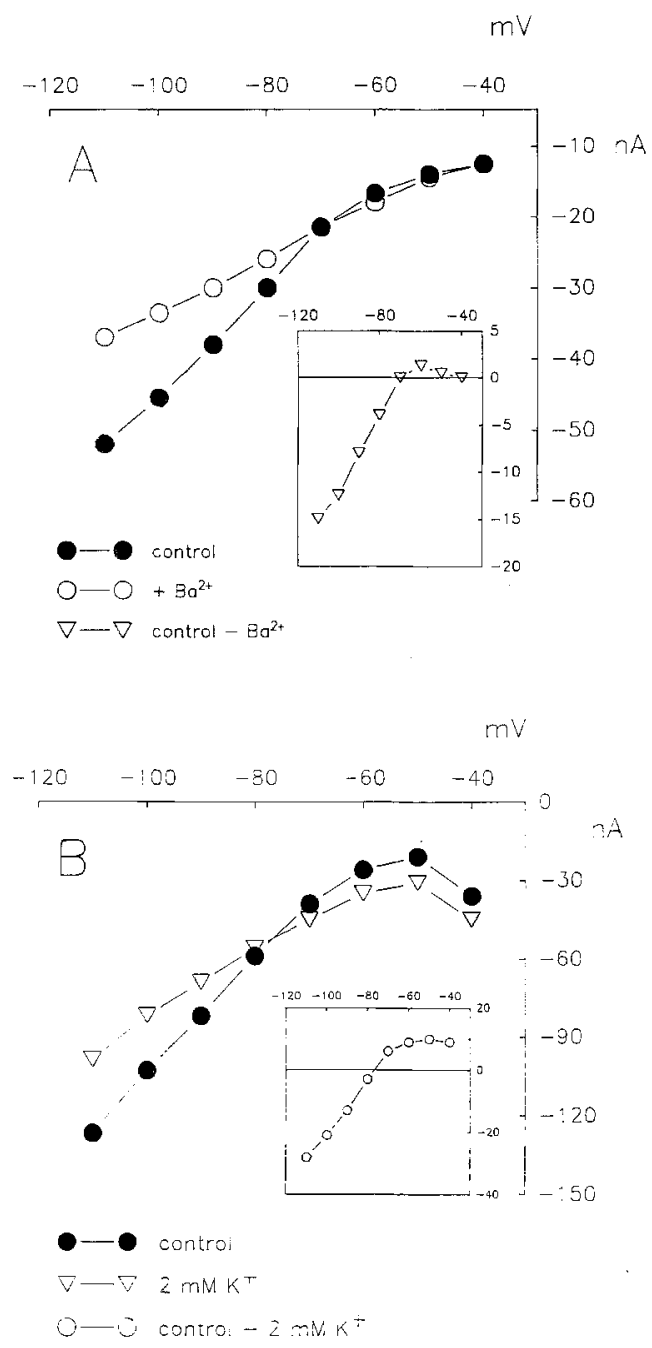

Fig. 1. $\mathrm{Ba}^{2+}$ or low extracellular $\mathrm{K}^{+}$reveal $I_{R}$ in giant neurons. $(A)$ Current-voltage curves were measured for the giant neuron, R2, under perfusion with control ASW (filled circles) or ASW + $0.5 \mathrm{mM} \mathrm{Ba}^{2+}$ (open circles). To determine the $I-V$ curve, voltage was stepped from the holding potential of $-50 \mathrm{mV}$ to command potentials from -110 to $-40 \mathrm{mV}$ for $0.5 \mathrm{sec}$. The current magnitude was measured at the end of each pulse and graphed as function of the command potential. The current remaining in the presence of $\mathrm{Ba}^{2+}$ was designated "leak" current. In the inset graph, the $I-V$ curve for this leak current was subtracted from the control ASW $I$ - $V$ curve to yield a leak-subtracted $I-V$ curve for control ASW (open triangles). This leak-subtracted current was assumed to be due solely to $I_{R}$. In subsequent figures, the leak current in the presence of $0.5-1 \mathrm{mM} \mathrm{Ba}^{2+}$ was measured in this voltage range and subtracted from the total current to illustrate changes specific for $I_{R}$. $(B) I-V$ curves for the giant neuron, LP1, were measured as described in $A$ under perfusion of control ASW (10 $\mathrm{mM} \mathrm{K}^{+}$, filled circles), or ASW with $2 \mathrm{mM} \mathrm{K}^{+}$(open inverse triangles). The difference curve, or current change due to lowering $\left[\mathrm{K}^{+}\right]$, is depicted in the inset graph (open circles)

The current not blocked by barium was designated undefined or "leak" current. Leak current measured in the presence of barium was subtracted from $I-V$ curves to isolate $I_{R}$. This leak subtraction procedure (depicted in Fig. $1 A$ ) was used routinely to identify changes specific to $I_{R}$. Changes in $I_{R}$ present at potentials more depolarized than -70 $\mathrm{mV}$ were not analyzed due to the presence of undefined contaminating currents. To determine the amount of current due to $I_{R}$ in giant neurons at rest, the slope conductance of the $I-V$ curve from -110 to $-70 \mathrm{mV}$ was compared before and after exposure to barium in control ASW (example in Fig. 1). At rest, $I_{R}$ was found to account for $48 \pm 2 \%(n=32)$ of the total conductance at voltages more hyperpolarized than $E_{\mathrm{K}}$. This proportion of $I_{R}$ was found to be generally typical of other Aplysia neurons tested (e.g., medial cells of the pleural ganglia, B1 of the buccal ganglion, and R14 of the abdominal ganglion). A larger amount of resting $I_{R}$ was found only in R15 $[6,33]$ and left upper quadrant neurons of the abdominal ganglion (this study).

\section{Modulators of AA Metabolism Alter $I_{R}$ 4-bromophenacylbromide}

In the accompanying paper, BPB was shown to inhibit the liberation of arachidonic acid from phospholipid. Application of BPB by perfusion to the bath was found to stimulate $I_{R}$ in giant neurons ( $n=$ 8 , examples for 20 and $50 \mu \mathrm{M} \mathrm{BPB}$ are in Fig. 2). The current induced by BPB displayed the inward rectification characteristic of $I_{R}$ (inset graph, Fig. $2 A$ ), and this induced current was inhibited with $\mathrm{Ba}^{2+}$ (Figs. $2 B$ and 4). To determine the extent to which the BPB-induced conductance increase was due to a change in $I_{R}$, the slope conductance (from -110 to $-70 \mathrm{mV}$ ) was measured for $0.5 \mathrm{mM} \mathrm{Ba}^{2+}$ alone and $\mathrm{Ba}^{2+}$ plus BPB. Over $96 \%$ of the slope conductance increase induced with $50 \mu \mathrm{M} \mathrm{BPB}$ was inhibited with $\mathrm{Ba}^{2+}$. Also, the BPB-induced stimulation of $I_{R}$ did not reverse with up to $2.5 \mathrm{hr}$ of perfusion with control ASW (Fig. $2 B$ shows the BPBinduced increase in $I_{R}$ did not reverse with a $70 \mathrm{~min}$ wash). BPB is established as an irreversible inactivator of phospholipase $A_{2}[51,61]$, which is consistent with this irreversible stimulation of $I_{R}$.

To test whether the effect of BPB was directly on the giant neuron, BPB was applied to the giant neuron cell body in a gentle stream flowing by gravity from the broken tip of a microelectrode pipette. The location of the stream was monitored by addition of $0.2 \%(\mathrm{wt} / \mathrm{vol})$ fast green to the solution in the pipette. By altering the size of the pipette aperture, the stream width could be confined within the dimensions of the giant neuron cell body, and the rate of flow was adjusted to cause the stream to be diluted substantially (as determined by disappearance of the tracking die) within several hundred microm- 

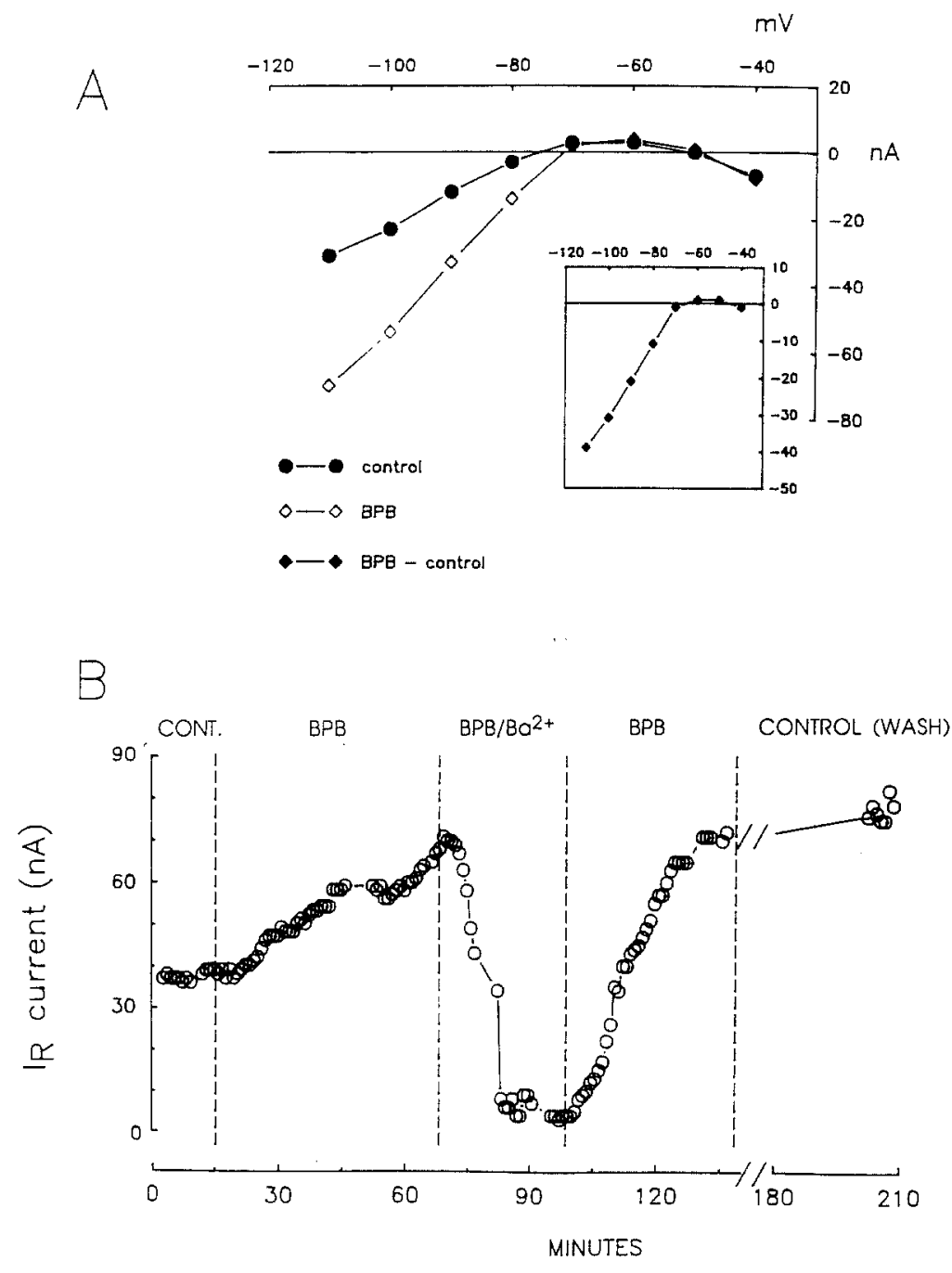

Fig. 2. Effect of BPB on $I_{R}$. (A) $I-V$ curves for LP1 (held at $-50 \mathrm{mV}$ ) under perfusion with control ASW (filled circles) or ASW + $20 \mu \mathrm{M}$ BPB (open diamonds) were measured and leak-subtracted as described in Fig. 1. Therefore, the current in the $I-V$ curves for this (and all subsequent figures) is due solely to $I_{R}$. The curve in the presence of $\mathrm{BPB}$ was measured $80 \mathrm{~min}$ after the start of perfusion with BPB. The difference curve, or BPB-induced current, is depicted in the inset graph (filled diamonds). $(B)$ In a separate experiment, 0.5 -sec pulses from -50 to -100 $\mathrm{mV}$ were used to follow the time course of the effect of BPB on $I_{R}$. The dotted lines indicate a change in experimental conditions. The labels above the graph depict the following sequence of conditions: control ASW; $+50 \mu \mathrm{M} \mathrm{BPB} ;+\mathrm{BPB}+0.5 \mathrm{mM} \mathrm{Ba}^{2+}$; $\mathrm{BPB}$ alone; control ASW wash eters away from the pipette tip. This created a small "plume" of perfusate that could be localized on the giant neuron cell body. Such a plume of BPB-containing perfusate $(50-100 \mu \mathrm{M})$ was found to stimulate $I_{R}$ in a manner identical to that described for bath-applied BPB $(n=14)$.

\section{Indomethacin}

Indomethacin was also found to increase $I_{R}$ in giant neurons ( $n=31$, examples for $50-150 \mu \mathrm{M}$ indomethacin in Figs. 3 and 4). The indomethacin-induced current was inwardly rectifying around $E_{\mathrm{K}}$ (inset graph, Fig. $3 A$ ), and was blocked by $\mathrm{Ba}^{2+}$ (Figs. $3 B$ and 4), and by lowering potassium from 10 to $2 \mathrm{~mm}$ (data not shown). Determined as described for BPB, $93 \%$ of the indomethacin-induced slope conductance increase was due to an increase in $I_{R}$. Also, as described for BPB, indomethacin was equally effective when its application was confined to the giant neuron cell body $(n=5)$. However, unlike $\mathrm{BPB}$, the effect of indomethacin was readily reversible when applied by bath (Figs. $3 B$ and 4 ) or cell-body-localized perfusion. This reversibility allowed a test of the accuracy of cell body perfusion, which proved quite precise. Reversal of the indomethacin-induced stimulation of $I_{R}$ began immediately upon removal of the perfusion plume, even if the plume was simply moved just out of range of the cell body.

The dose dependence for the effect of indomethacin on $I_{R}$ is depicted in Fig. 5. Indomethacin was consistently stimulatory above $10 \mu \mathrm{M}$, and this effect saturated by $250 \mu \mathrm{M}$. At saturation, $I_{R}$ was increased over fivefold. Also, a saturating dose of indomethacin occluded the effect of BPB, suggesting these agents are acting through the same pathway to modulate $I_{R}$.

Indomethacin is known to be an inhibitor of cyclooxygenase [20], which catalyzes the first step for conversion of AA to prostaglandins and thrombox- 

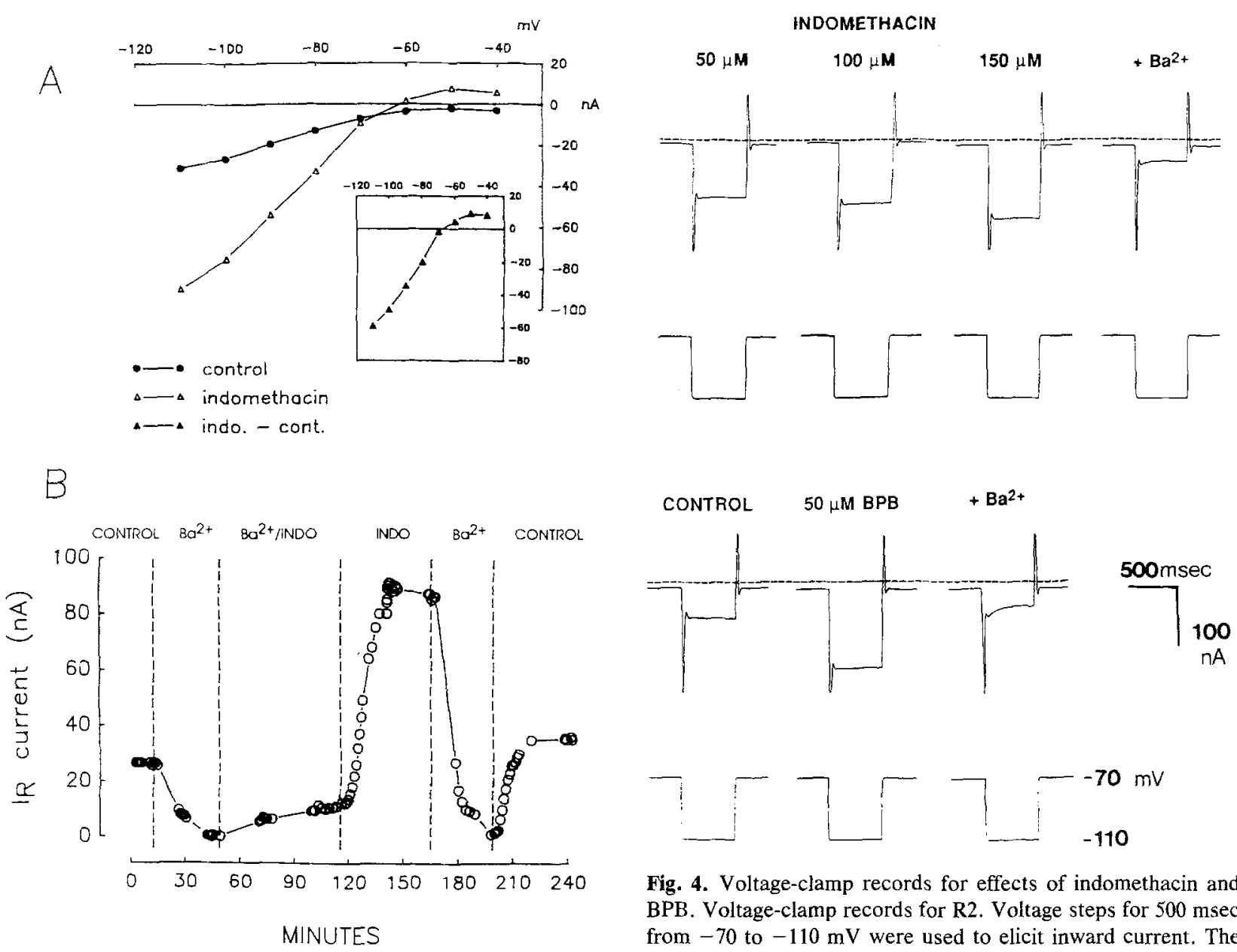

Fig. 4. Voltage-clamp records for effects of indomethacin and BPB. Voltage-clamp records for R2. Voltage steps for $500 \mathrm{msec}$ from -70 to $-110 \mathrm{mV}$ were used to elicit inward current. The steady-state inward currents resulting from this voltage step are shown for each condition tested. Recording began under perfusion of $50 \mu \mathrm{M}$ indomethacin (due to a previous experiment with indomethacin in an adjacent neuron in the same ganglion). The concentration of indomethacin for perfusion was increased to $100 \mu \mathrm{M}$ and then to $150 \mu \mathrm{M}$. Approximately $30 \mathrm{~min}$ of perfusion was required to reach a new steady state in inward current for each change; much of this time was required for the bath to attain the new concentration. In the presence of $150 \mu \mathrm{M}$ indomethacin, the addition of $0.5 \mathrm{~mm} \mathrm{BaCl}$ decreased the inward current by over $73 \%$. Subtraction of the current magnitude at the end of the pulse, with and without $\mathrm{Ba}^{2+}$, revealed that of the $134 \mathrm{nA}$ of inward current elicited by hyperpolarization in the presence of $150 \mu \mathrm{M}$ indomethacin, $98 \mathrm{nA}$ were due to $I_{R}$. Subsequently, both indomethacin and $\mathrm{Ba}^{2+}$ were removed by perfusion with control ASW for about $1 \mathrm{hr}$. After this wash, the steady-state $I_{R}$ was reduced to $21 \mathrm{nA}$ out of a total of $57 \mathrm{nA}$ of inward current. The giant neuron was then exposed to $50 \mu \mathrm{M} \mathrm{BPB}$ by perfusion for 1 $\mathrm{hr}$, and the BPB was removed by perfusion with control AWS. Subsequent addition of $0.5 \mathrm{mM} \mathrm{Ba} \mathrm{Ba}^{2+}$ inhibited $72 \%$ of the inward current. Therefore, of the $147 \mathrm{nA}$ of inward current induced by hyperpolarization after exposure to BPB (labeled $50 \mu \mathrm{M} \mathrm{BPB}$ ), $106 \mathrm{nA}$ due to $I_{R}$, which is a fivefold increase in $I_{R}$ relative to control

clooxygenase [20]; however, we observed no fect of this inhibitor at up to $50 \mu \mathrm{M}$. We also tested the effect of nordihydroguaiaritic acid on $I_{R}$. NDGA is known to inhibit lipoxygenase catalyzed peroxylation and hydroxylation of AA [63] and has been reported to inhibit this activity in Aplysia [48]. We did not observe any effect of NDGA on $I_{R}$ at up to $50 \mu \mathrm{M}$. In each case, after testing for the effects

of these inhibitors, a robust effect of either indomethacin or BPB was observed.

Although a saturating dose of indomethacin occluded the effect of BPB on $I_{R}$, indomethacin did 


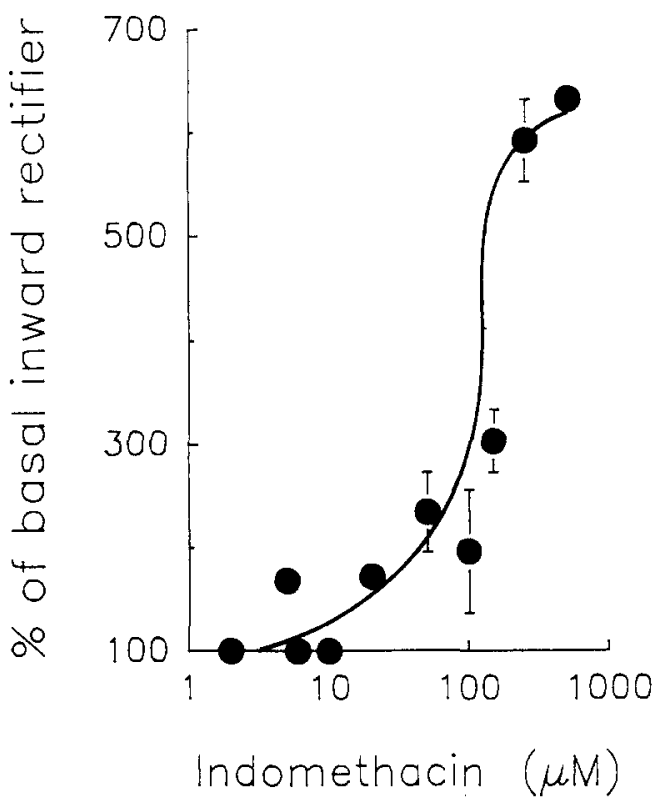

Fig. 5. Dose-response for stimulation of $I_{R}$ by indomethacin. The effect of indomethacin on $I_{R}$ was determined as function of concentration. $I-V$ curves were measured and leak subtracted as described in Fig. 1. Slope conductances for leak-subtracted $I-V$ curves from giant neurons were measured from -70 to -110 $\mathrm{mV}$. The slope conductance is expressed as the percent of conductance due to $I_{R}$ at rest. This normalization is termed $\%$ of basal inward rectifier on the ordinate axis. The curve was fitted by hand, and the depiction of saturation is supported by experiments in which an increase in indomethacin from 250 to $500 \mu \mathrm{M}$ did not produce any increase in $I_{R}(n=2)$

not have the same effect as BPB on AA metabolism in Aplysia ganglia. At concentrations up to $250 \mu \mathrm{M}$, indomethacin did not consistently alter the redistribution of radioactivity which occurred with 50 $\mu \mathrm{M}$ exogenous AA chase. However, indomethacin $(250 \mu \mathrm{M})$ was found to inhibit uptake of AA into storage lipids. Figure 6 depicts the uptake of AA from medium containing $0.5 \mu \mathrm{M} \mathrm{AA}$ (sp act, $40 \mathrm{mCi} /$ mmol), with and without indomethacin. Uptake into total phospholipid did not show a significant change, while uptake into neutral lipid was inhibited $68 \%$, and the radioactivity in internal free AA was fourfold greater in the presence of indomethacin.

\section{2-O-tetradecanoylphorbol-13-acetate}

The phorbol ester, TPA, was found to inhibit $I_{R}(500$ nM, $n=8$, example in Fig. $7 A$ ). 500 nм TPA has been shown to stimulate maximally the liberation of AA from phospholipid storage, which increases intracellular free AA and greatly increases the release of free AA and eicosanoids into the extracellular medium [11]. Over $85 \%$ of the conductance de-

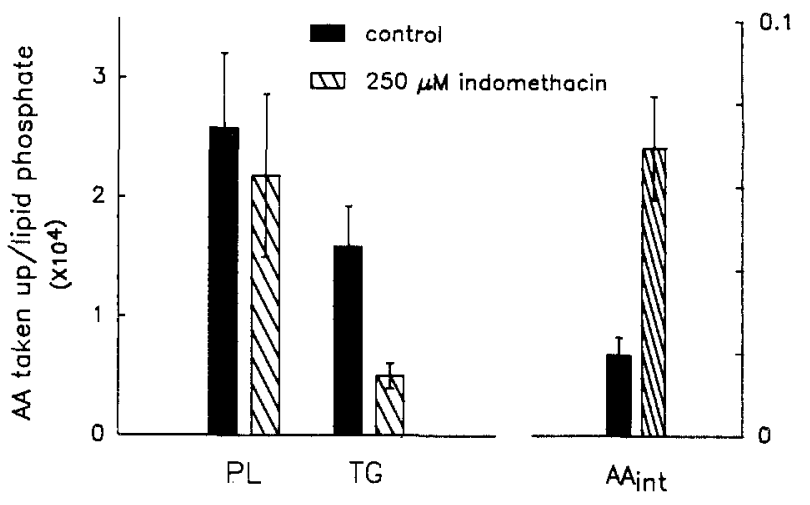

Fig. 6. Effect of indomethacin on uptake of AA. Pleuropedal ganglia were incubated in $0.5 \mu \mathrm{M} \mathrm{AA}$ (sp act $4.0 \mathrm{Ci} / \mathrm{mmol}$ ) in ASW with $0.05 \%$ (wt/vol) BSA for $2 \mathrm{hr}$ with $250 \mu \mathrm{M}$ indomethacin (diagonal), or ASW with $0.1 \%$ (vol/vol) carrier DMSO (solid). AA uptake into total phospholipid, total neutral lipid, and internal free AA was normalized to ganglionic lipid phosphate. Bars and error bars are the mean and SD of measurements from four ganglia. For a description of the techniques used for lipid analysis, see Materials and Methods of the accompanying paper [11]

crease with TPA was due to inhibition of $I_{R}$ (determined with and without $\mathrm{Ba}^{2+}$, as described for BPB). This inhibition was on average a $40 \pm 25 \%$ reduction of $I_{R}$ at rest and was completely reversible with wash.

To see if TPA could inhibit the effect of indomethacin, a ganglion was first exposed to perfusion with TPA, then TPA and indomethacin, and finally indomethacin alone. Steady state $I-V$ curves for each of those conditions are depicted for a representative experiment in Fig. $7 B$. The stimulatory effect of indomethacin was decreased $64 \pm 35 \%$ in the presence of TPA ( $n=4$ for $50-60 \mu \mathrm{M}$ indomethacin and $500 \mathrm{nM}$ TPA), suggesting indomethacin (and BPB, by inference) and TPA are acting through a common pathway to affect $I_{R}$.

\section{INTERACTION BETWEEN INHIBITORS OF AA Metabolism AND $c$ AMP}

In Aplysia neuron R15, serotonin (5HT) has been shown previously to modulate $I_{R}$ through $c$ AMP [2, $6,19]$. 5HT binds cell surface receptors to activate adenylate cyclase and thereby increase intracellular cAMP, which initiates a cascade of steps leading to an increase in $I_{R}$. We also found $I_{R}$ in the giant neurons was increased with 5HT, as Gunning [22] reported previously. This stimulatory effect of $5 \mathrm{HT}$ was found to saturate at $50 \mu \mathrm{M}$.

We were interested in the possibility that the pharmacological agents used in this study were act- 

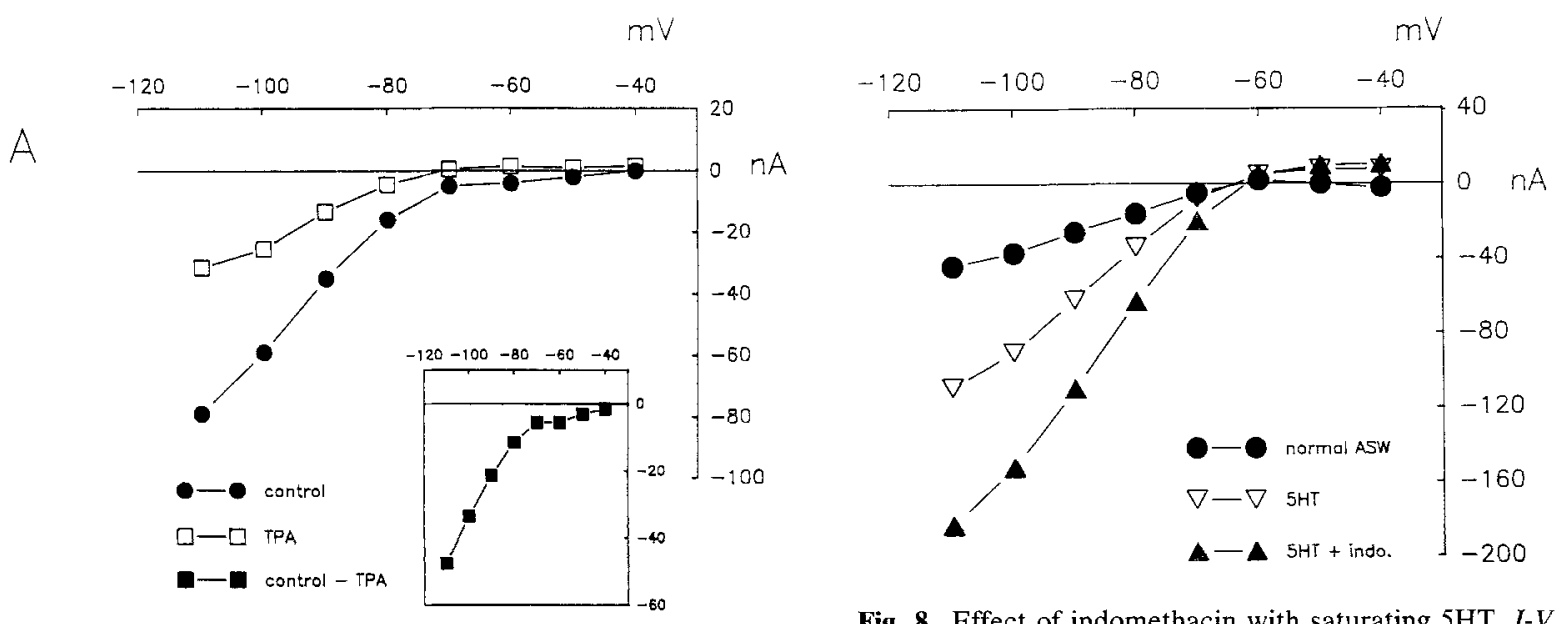

Fig. 8. Effect of indomethacin with saturating 5HT. $I$ - $V$ curves for R2 under perfusion with control ASW (filled circles), ASW +

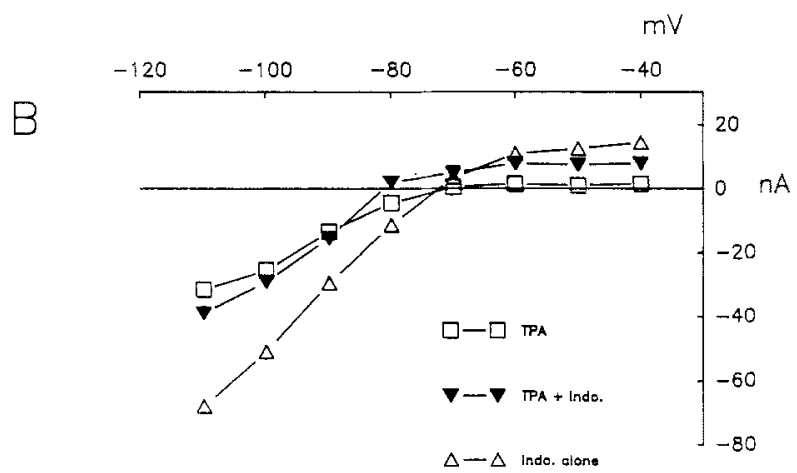
$50 \mu \mathrm{M}$ 5HT (open inverse triangles), or $50 \mu \mathrm{M} 5 \mathrm{HT}+50 \mu \mathrm{M}$ indomethacin (filled triangles) were measured and leak subtracted as described in Fig. $1.50 \mu \mathrm{M} 5 \mathrm{HT}$ was determined to be a saturating dose for stimulation of $I_{R}$ (data not shown)

Fig. 7. Effect of TPA on $I_{R}$. (A) $I-V$ curves for LP1 (held at -50 $\mathrm{mV}$ ) under perfusion with control ASW (filled circles) or $500 \mathrm{nM}$ TPA (open squares) were measured and leak subtracted as described in Fig. 1. $I-V$ curve in the presence of TPA was measured after 45 min of perfusion with TPA. The difference curve, or TPA-inhibited current, is depicted in the inset graph (filled squares). (B) The effect of indomethacin in the presence of 500 nM TPA was determined. $I-V$ curves were measured for LP1 in the presence of the following conditions (in sequence): $500 \mathrm{nM}$ TPA (open squares, same as in $A$ ); $500 \mathrm{nM}$ TPA $+60 \mu \mathrm{M}$ indomethacin (filled inverse triangles); $60 \mu \mathrm{M}$ indomethacin alone (open triangles)

ing through the $c$ AMP cascade to modulate $I_{R}$. Interaction at the level of the $5 \mathrm{HT}$ receptor was addressed first. Saturating 5HT did not block the indomethacin- or BPB-induced increase in $I_{R}$. In fact, the stimulatory effect of indomethacin was apparently unattenuated in the presence of saturating 5HT (Fig. 8). These results preclude the 5HT receptor as the site of action of indomethacin, or, by inference, of the other modulators of AA metabolism. However, these agents could be acting at a point downstream from 5HT receptor-linked adenylate cyclase activation. A combination of the adenylate cyclase activator forskolin and the phosphodiesterase inhibitor isobutylmethylxanthine was used to bypass cell surface receptor activation of

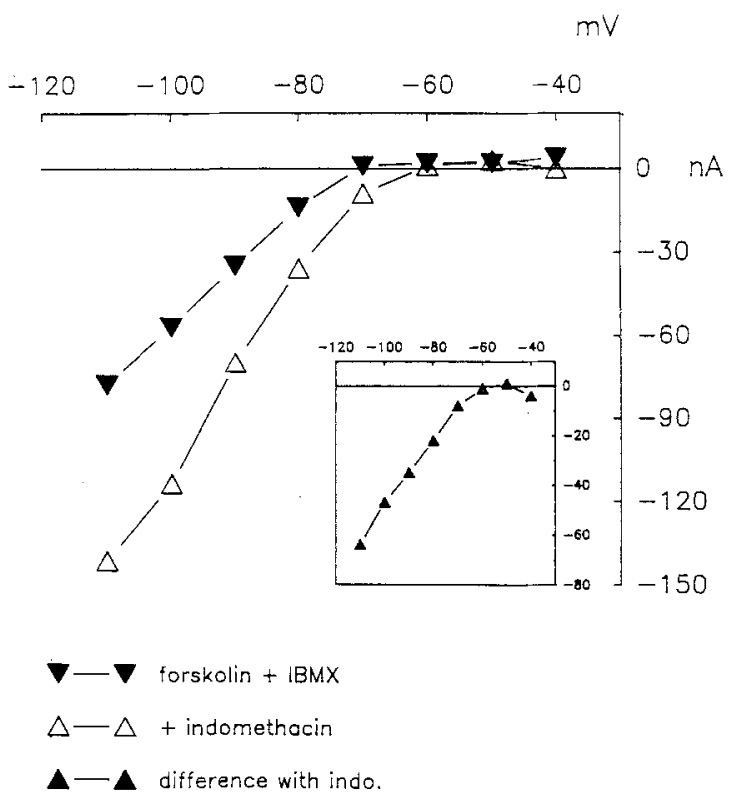

Fig. 9. Effect of indomethacin with maximally stimulated adenylate cyclase. $I-V$ curves for $\mathrm{R} 2$ in the presence of forskolin ( 50 $\mu \mathrm{M})$ and IBMX $(200 \mu \mathrm{M})$ in concentrations sufficient to occlude the stimulatory effect of $50 \mu \mathrm{M} 5 \mathrm{HT}$ (data not shown). I-V curves (measured and leak-subtracted as described in Fig. 1) in the presence of forskolin and IBMX (filled inverse triangles), or forskolin and IBMX $+150 \mu \mathrm{M}$ indomethacin (open triangles) are shown. Indomethacin-induced current is depicted in the inset graph (filled triangles)

adenylate cyclase. Doses of these drugs, sufficient to occlude the effect of a saturing dose of $5 \mathrm{HT}$, did not block the response of $I_{R}$ to indomethacin (50$150 \mu \mathrm{M}$, Fig. 9). Therefore, under conditions of po- 


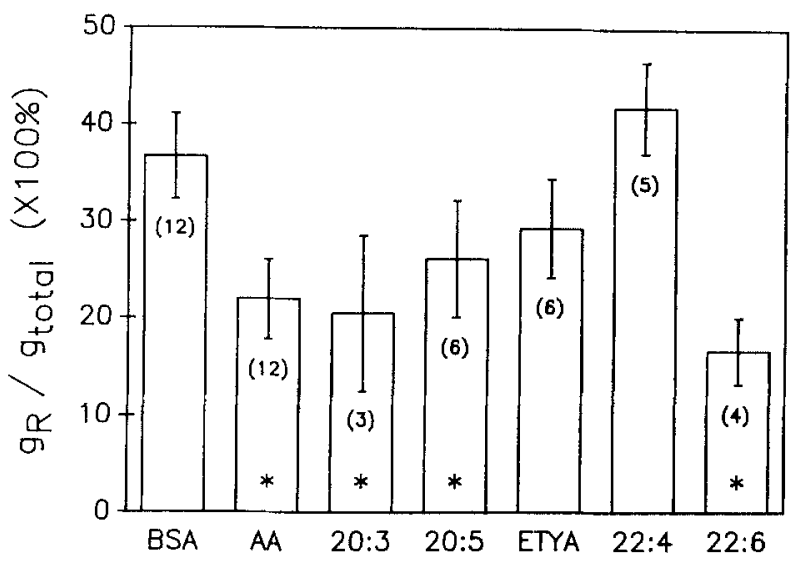

Fig. 10. The effect of dialysis with $A A$ and other unsaturated fatty acids on $I_{R}$. Groups of four to eight abdominal and/or left pleuropedal ganglia were placed in dialysis tubing and dialyzed in perfusion medium for $40-46 \mathrm{hr}$ as described in Materials and Methods. The mean inward rectifier conductance (expressed as percent of the total conductance to normalize for cell size differences) was determined for dialysis in perfusion medium alone $\left(g_{R} / g_{\text {total }}=31.1+2.1 \mathrm{sE} \%, n=6\right.$, not graphed $)$, or with $0.05 \%$ (wt $/ \mathrm{vol}$ ) BSA, or BSA with $20 \mu \mathrm{M}$ of fatty acid. The abbreviated names of the fatty acids tested are listed under the graph: $B S A=$ BSA alone; $20: 3=$ eicosatrienoic acid $(\omega 9) ; 20: 5=$ eicosapentaenoic acid $(\omega 3) ; E T Y A=$ eicosatetraynoic acid; $22: 4=$ docosatetrenoic acid $(\omega 3) ; 22.6=$ docosahexaenoic acid $(\omega 3)$. The number of measurements averaged are listed in parentheses. An asterisk $(*)$ indicates the mean $g_{R}$ was significantly different from the control at the $99 \%$ confidence level (BSA only) as determined by student's $t$ test

tent adenylate cyclase activation and phosphodiesterase inhibition, $I_{R}$. was still stimulated with indomethacin, suggesting a mechanism of activation of $I_{R}$ independent of $c$ AMP metabolism.

\section{Dialysis with AA ANd Other Fatty Acids}

Direct application of AA (up to $50 \mu \mathrm{M}$ ) did not consistently produce changes in $I_{R}$. However, longterm incubation in AA was found to inhibit $I_{R}$. Ganglia were placed in dialysis tubing for dialysis in ASW supplemented with a diluted nutrient medium (termed perfusion medium; described in Materials and Methods), either alone, with BSA, or with BSA and $20 \mu \mathrm{M}$ AA or other unsaturated fatty acids (at $10^{\circ} \mathrm{C}$ for $40-46 \mathrm{hr}$ ). Following dialysis, the ganglia were desheathed and the inward rectifier conductance of the giant neurons was measured. The mean inward rectifier conductances (expressed as percent of total conductance to normalize for differences in cell sizes) for each condition are compared in Fig. 10 . In the presence of $20 \mu \mathrm{M} \mathrm{AA}, I_{R}$ was inhibited $\sim 40 \%$ relative to dialysis with $\mathrm{BSA}$ alone. However, several other unsaturated fatty acids were equally as effective for inhibition of $I_{R}$, including eicosatrienoic (20:3 $\omega 9)$, eicosapentaenoic $(20: 5 \omega 3)$,

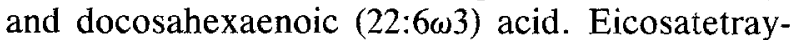
noic acid (ETYA) and docosatetraenoic acid $(22: 4 \omega 6)$ were the only fatty acids tested which did not produce a significant change in $I_{R}$.

\section{Effects of Prolonged Perfusion on $I_{R}$}

TPA and BPB altered $I_{R}$ in ways consistent with the activity of these substances on AA metabolism [11]. The fact that BPB had a potent effect on $I_{R}$ in the resting state suggested that the constant AA turnover (described in the companion paper [11]) may be providing free AA to mediate constitutive inhibition of $I_{R}$. To test this idea, we attempted to deplete the giant neuron of stored $\mathrm{AA}$, reasoning that if $\mathrm{AA}$ was involved in inhibition of $I_{R}$ in the resting state, then loss of stored AA might reveal some of this constitutively inhibited $I_{R}$. With the knowledge that AA is continuously released from storage in ganglia, we used extended perfusion with BSA to strip the giant neurons of AA, and tested the effect of this perfusion on the magnitude of $I_{R}$.

Steady-state $I_{R}$ was measured in giant neurons in freshly dissected and desheathed ganglia, and then the ganglia were placed under perfusion with perfusion medium for $\sim 12 \mathrm{hr}$. Finally, the ganglia were placed under perfusion with control ASW, and the steady-state $I_{R}$ of the giant neurons was measured again. As shown in Fig. 11, after this protocol with perfusion medium alone, the mean $I_{R}$ was decreased. However, if $0.5 \mathrm{mg} / \mathrm{ml} \mathrm{BSA}$ was added to the perfusion medium, $I_{R}$ was significantly larger after $12 \mathrm{hr}$ of perfusion (Fig. 11).

To test whether this effect of perfusion with BSA could be due to loss of AA, the protocol was repeated with perfusion medium containing BSA and 5-10 $\mu \mathrm{M}$ AA. As depicted in Fig. 11, the addition of AA substantially decreased the stimulatory effect of perfusion with BSA alone. Conversely, we hypothesized that a decrease in phospholipase activity might limit the amount of AA lost and thereby decrease the stimulatory effect of perfusion with BSA. In fact, pretreatment of giant neurons with BPB completely abolished the effect of perfusion with BSA (Fig. 11).

\section{Discussion}

\section{Pharmacological Agents Alter AA METABOLISM AND $I_{R}$}

In the preceding paper [11], constant turnover of internal free AA was demonstrated in Aplysia gan- 


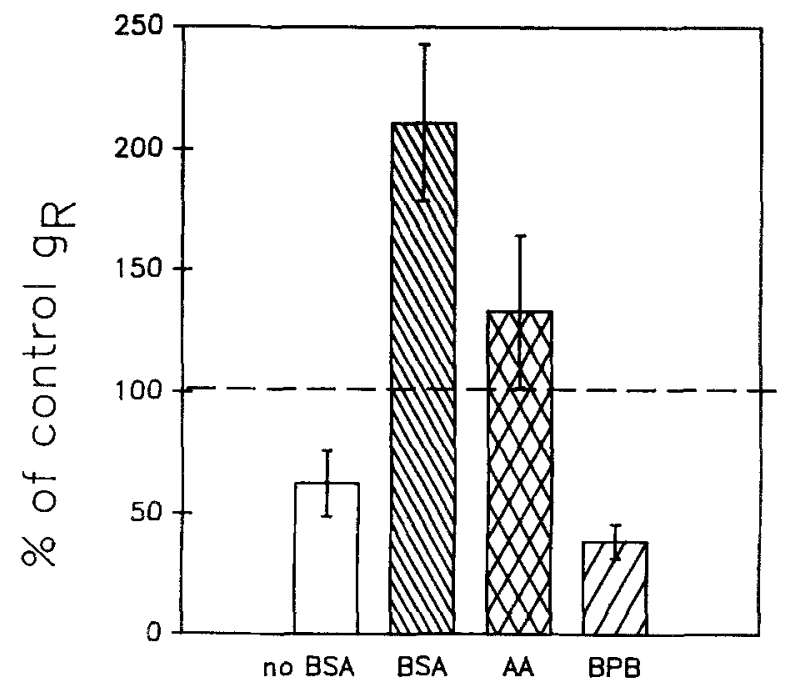

(8) (8) (11) (4)

Fig. 11. The effect of extended perfusion on $I_{R}$. Ganglia were prepared for extended perfusion as described in Materials and Methods. Groups of four to eight abdominal and/or left pleuropedal ganglia were pinned out and desheathed on a single plate. The plate was placed under perfusion with sterile, control ASW. The giant neurons were successively placed under voltage clamp (held at $-50 \mathrm{mV}$ ), the time for the start of voltage clamp for each was noted, and the resting steady-state inward rectifier conductance was measured. This initial conductance was compared to the inward rectifier conductance measured again in the same cell after perfusion for $12 \mathrm{hr}$ with sterile perfusion medium (described in Materials and Methods) alone (blank), or containing $0.05 \%$ (wt/vol) BSA (left diagonal), or BSA and 5-10 $\mu \mathrm{M} \mathrm{AA} \mathrm{(cross-}$ hatch), or with BSA after pretreatment with $100 \mu \mathrm{M}$ BPB for 30 min (right diagonal). Inward rectifier conductance for giant neurons treated with BPB was measured initially before exposure to BPB

glia. We concluded the constant release of free AA and eicosanoids that accompanied this turnover was too large to be solely the result of futile cycling. Therefore, we hypothesized that the free AA or eicosanoids provided by this constant turnover must have a physiological role. In this paper, we have identified constitutive inhibition of $I_{R}$ as a potential role. This conclusion is based in part upon a correlation between the effects of several pharmacological agents on $I_{R}$ on the one hand, and on AA metabolism on the other. BPB, an inhibitor of AA turnover, activated $I_{R}$, and TPA, a stimulator of AA turnover, inhibited $I_{R}$.

$B P B$ has been shown to inhibit liberation of AA from phospholipid and decrease internal free $\mathrm{AA}$ in Aplysia [11]. At rest, $I_{R}$ was stimulated with BPB, suggesting that inhibition of phospholipase activity and a concomitant decrease in availability of free AA resulted in stimulation of $I_{R}$. Therefore, resting phospholipase activity must be high enough to provide sufficient free AA to maintain constitutive inhibition of $I_{R}$, which is revealed in the presence of $B P B$. Although BPB is a fairly nonspecific alkylating agent, the widespread evidence that $\mathrm{BPB}$ is an effective inhibitor of $\mathrm{PLA}_{2}$, both in vivo and in vitro (see accompanying paper [11] for references), supports the likelihood that $\mathrm{BPB}$ is acting through this pathway in the giant neurons.

The results with TPA support this model. TPA has been shown to stimulate liberation of AA from phospholipid in Aplysia nervous system and TPA has been shown to inhibit $I_{R}$. If TPA acts by stimulating phospholipase activity, this means that the resting activity, although high, is not maximal. That is, the resting phospholipase activity is high enough to shut down most, but not all, of the potentially available $I_{R}$. If all of the constitutively inhibited $I_{R}$ is revealed with a saturating dose of indomethacin, then over $80 \%$ of the potentially available $I_{R}$ is inhibited at rest.

Indomethacin is often used to selectively inhibit prostaglandin synthesis. Piomelli et al. [48] reported that prostaglandin $\mathrm{E}_{2}$ production in Aplysia nervous system was inhibited by indomethacin with an $\mathrm{IC}_{50}$ value of $0.5 \mu \mathrm{M}$. We found the half maximal concentration for indomethacin-induced stimulation of $I_{R}$ was about $100 \mu \mathrm{M}$, which is not consistent with indomethacin acting as selective inhibitor of prostaglandin production as the mechanism for stimulation of $I_{R}$. High concentrations $(100-500 \mu \mathrm{M})$ of indomethacin have been shown to inhibit phospholipase activity $[21,25,34,50]$, diacylglycerol lipase activity [49] and AA uptake [35]. With $250 \mu \mathrm{M}$ indomethacin (saturating with respect to $I_{R}$ stimulation) we were only able to detect an effect on AA uptake. After two hours incubation in $0.5 \mu \mathrm{M}$ AA in the presence of indomethacin, radioactivity in the internal free AA pool was fourfold greater, and uptake into neutral lipid was decreased $68 \%$, while uptake into phospholipid was unchanged. If indomethacin specifically inhibited the fatty-acyl transferase which catalyzes esterification of AA-CoA into neutral lipid (see accompanying paper [11], Fig. 1, pathway $I I I$ ), we would expect to see an increase in uptake into phospholipid, and a smaller increase in internal free AA than observed. Therefore, specific inhibition of the fatty acyl-CoA synthetase (see accompanying paper [11], Fig. 1, pathway $I I$ ) accounts best for the effect of indomethacin. We would expect to see decreased AA-CoA in ganglia commensurate with the magnitude of inhibition of uptake into neutral lipid, a hypothesis soon to be tested. Neufield et al. [44] demonstrated that a mutant cell line lacking synthetase activity specific for AA was also deficient in prostaglandin production 
and bradykinin-stimulated liberation of AA from phospholipid. Therefore, acyl-CoA synthetase activity can be very important for regulation of free AA and the production of eicosanoids.

The conclusion that indomethacin is not likely acting as a specific cyclooxygenase inhibitor to stimulate $I_{R}$ is supported by the lack of effect of acetylsalicylic acid, another inhibitor of cyclooxygenase. Furthermore, this means prostaglandins are not likely responsible for inhibition of $I_{R}$. At concentrations from 25-100 $\mu \mathrm{M}$, indomethacin has been shown to inhibit both cyclooxygenase and lipoxygenase activity $[7,10,53,55,57]$. However, if indomethacin is acting through inhibition of lipoxygenases, the lipoxygenase inhibitor NDGA also should have stimulated $I_{R}$, but it was found to be ineffective. The available evidence is most consistent with the conclusion that free AA is involved in constitutive inhibition of $I_{R}$, and that the eicosanoids produced likely have another physiological role.

\section{Altering AA in Storage Affects $I_{R}$}

AA has been shown to have direct effects on cellular physiology, particularly with regard to AA-induced mobilization of intracellular calcium $[4,14$, $17,32,42,52,62,64]$. In permeabilized pancreatic islet cells, intracellular calcium was mobilized with $\mathrm{AA}$ in a manner similar to that produced by $\mathrm{IP}_{3}[60$, 62]. Direct application of AA has been shown to activate potassium currents in several systems. In patch-clamp studies of Aplysia sensory neurons, AA increased the open probability of individual Schannels [48]. Most recently, outwardly rectifying potassium currents of heart and smooth muscle cells under patch clamp were observed to be activated directly by $\mathrm{AA}$ and other unsaturated fatty acids $[30,46]$.

In addition to the pharmacological evidence, a direct indication of AA involvement in inhibition of $I_{R}$ came from the experiments using extensive perfusion. The observed constitutive release of AA [11] suggested extensive perfusion of ganglia with BSA should remove stored AA, and disinhibit $I_{R}$. Such perfusion did in fact increase $I_{R}$, and this stimulation was decreased by including AA in the perfusion medium, or by pretreatment with BPB. Paradoxically, extensive perfusion without BSA led to a decrease in $I_{R}$. We do not know the cause of this; however, we plan to investigate the possibility that extensive perfusion may lead to "calcium-loading" due to decreased membrane resistance. Extensive perfusion was often observed to increase the leak current in the giant neuron (data not shown). The increase in intracellular calcium which likely ac- companies the increased leak current could activate phospholipase, leading to an increase in internal free AA and inhibition of $I_{R}$.

The effect of BPB on the perfusion-induced activation of $I_{R}$ was determined by comparing inward rectifier conductance before exposure to $\mathrm{BPB}$ to the conductance after BPB pretreatment and perfusion with BSA for $\sim 12 \mathrm{hr}$. Like perfusion with no BSA, the inward rectifier conductance in giant neurons treated with BPB was actually smaller after overnight perfusion with BSA. Again, we cannot explain this phenomenon, but BPB clearly prevents any increase in conductance, consistent with inhibition of phospholipase.

Exogenous AA did not affect $I_{R}$ when applied acutely during electrophysiological recording, consistent with the finding that exogenous AA did not increase the apparent size of the internal free AA pool [11]. Kim and Clapham also found that AA was ineffective for activation of an atrial potassium channel when added extracellularly or added to the pipette in cell-attached patches; this potassium channel was activated only with application of AA to inside-out patches [30]. However, we found that $I_{R}$ was smaller after extensive dialysis in AA-containing medium. With AA, inhibition of $I_{R}$ was observed after $24 \mathrm{hr}$ of dialysis (data not shown), although the inhibition was more significant after $\sim 40$ hr. This time dependence may be explained by a gradual increase in the size of the AA storage pools with dialysis, which may lead to elevated internal free AA and inhibition of $I_{R}$. Cells in culture have been shown to slowly increase the AA content of lipids when excess AA is available in the medium [59]. McGee et al. [41] recently reported that enrichment of phospholipids with AA altered the gating kinetics of a delayed rectifier potassium channel in a neuroblastoma $x$ glioma cell line.

$I_{R}$ was also found to be decreased after dialysis with other polyunsaturated fatty acids. These fatty acids were chosen for testing because of their similarity to AA, based upon their ability to undergo catalysis or compete with AA for catalysis by eicosanoid-producing enzymes $[9,18,37]$, and because of their reported presence in Aplysia nervous system [48]. Therefore, although AA may not exclusively mediate inhibition of $I_{R}$, the predominance of AA in phospholipids in Aplysia relative to the other fatty acids tested [48] suggests AA likely has the most significant physiological role.

\section{AA- AND $c$ AMP-MEdiated Modulation of $I_{R}$}

The cAMP-mediated activation and AA-mediated inhibition of $I_{R}$ that we report is reminiscent of findings for the serotonin-sensitive potassium current 
$\left(I_{S}\right)$ in Aplysia sensory neurons. In these cells, 5HT acts through $c$ AMP to inhibit $I_{S}[54,56]$, and the tetrapeptide FMFRamide acts through AA to activate the same current $[48,47]$. AA and $c$ AMP can interact at the level of the channel to modulate the same population of $I_{S}$ channels in sensory neurons, as demonstrated in cell-attached patch recordings in which FMFRamide could open S-channels closed by 5HT-induced elevation of cAMP [5]. In the present paper, modulators of AA metabolism were found to alter $I_{R}$ without acting through $c$ AMP metabolism. One explanation for the additivity of the effects of cAMP and the modulators of AA metabolism is that AA may mediate inhibition of a population of $I_{R}$ channels distinct from the population regulated by $c$ AMP. However, the molecular mechanism of AA-mediated inhibition of $I_{R}$ remains to be determined.

This work was supported by NIH grant NS17910 to I.B.L. We are grateful to Richard Kramer and Stephen Lin for their helpful technical advice.

\section{References}

1. Abou-Samra, A.B., Harwood, J.P., Catt, K.J., Aguilera, G. 1987. Mechanisms of action of CRF and other regulators of ACTH release in pituitary corticotrophs. Ann. N.Y. Acad. Sci. 512:67-84

2. Adams, W.B., Levitan, I.B. 1982. Intracellular injection of protein kinase inhibitor blocks the serotonin-induced increase in $\mathrm{K}^{+}$conductance in Aplysia neuron R15. Proc. Natl. Acad. Sci. USA 79:3877-3880

3. Aguilera, G., Abou-Samra, A.B., Harwood, J.P., Catt, K.J. 1988. Corticotropin-releasing factor receptors: Characterization and actions in the anterior pituitary. Adv. Exp. Med. Biol. 245:83-105

4. Beaumier, L., Faucher, N., Naccache, P.H. 1987. Arachidonic acid-induced release of calcium in permeabilized human neutrophils. FEBS Lett. 221:289-292

5. Belardetti, F., Kandel, E.R., Siegelbaum, S.A. 1987. Neuronal inhibition by the peptide FMFRamide involves opening of S $\mathrm{K}^{+}$channels. Nature (London) 325:153-156

6. Benson, J.A., Levitan, I.B. 1983. Serotonin increases an anomalously rectifying $\mathrm{K}^{+}$conductance in Aplysia neuron R15. Proc. Natl. Acad. Sci. USA 80:3522-3526

7. Bray, M.A., Ford-Hutchinson, A.W., Shipley, M.E., Smith, M.J.H. 1980. Calcium ionophore A23187 induces release of chemokinetic and aggregating factors from polymorphonuclear leukocytes. Br. J. Pharmacol. 71:507-512

8. Camoratto, A.M., Grandison, L. 1985. Evidence supporting a correlation between arachidonic acid release and prolactin secretion from $\mathrm{GH}_{3}$ cells. Endocrinology 116:1506-1513

9. Campbell, W.B., Falck, J.R., Okita, J.R., Johnson, A.R., Callahan, K.S. 1985. Synthesis of dihomoprostaglandins from adrenic acid $(7,10,13,16$-docosatetraenoic acid) by human endothelial cells. Biochim. Biophys. Acta 837:67-76

10. Capdevila, J., Gil, L., Orellana, M., Marnett, L.J., Mason, J.I., Yadagiri, P., Falck, J.R. 1988. Inhibitors of cytochrome P-450-dependent arachidonic acid metabolism. Arch. Biochem. Biophys. 261:257-263
11. Carlson, R.O., Levitan, I.B. 1990. Regulation of intracellular free arachidonic acid in Aplysia nervous system. J. Membrane Biol. 116:249-260

12. Cashman, J.R. 1989. 5,6-Epoxyeicosatrienoic acid stimulates growth hormone release in rat anterior pituitary cells. Life Sci. 44:1387-1393

13. Cashman, J.R., Hanks, D., Weiner, R.I. 1987. Epoxy derivatives of arachidonic acid are potent stimulators of prolactin secretion. Neuroendocrinology 46:246-251

14. Chan, K., Turk, J. 1987. Mechanism of arachidonic acidinduced $\mathrm{Ca}^{2+}$ mobilization from rat liver microsomes. Biochim. Biophys. Acta 928:186-193

15. Chang, J.P., Graeter, J., Catt, K.J, 1986. Coordinate actions of arachidonic acid and protein kinase $\mathrm{C}$ in gonadotropinreleasing hormone-stimulated secretion of luteinizing hormone. Biochem. Biophys. Res. Commun. 134:134-139

16. Chang, J.P., Graeter, J., Catt, K.J. 1987. Dynamic actions of arachidonic acid and protein kinase $\mathrm{C}$ in pituitary stimulation by gonadotropin-releasing hormone. Endocrinology 120:1837-1845

17. Cheah, A.M. 1981. Effect of long chain unsaturated fatty acids on the calcium transport of sarcoplasmic reticulum. Biochim. Biophys. Acta 648:113-119

18. Corey, E.J., Shih, C., Cashman, J.R. 1983. Docosahexaenoic acid is a strong inhibitor of prostaglandin but not leukotriene biosynthesis. Proc. Natl. Acad. Sci. USA 80:3581-3584

19. Drummond, A., Benson, J., Levitan, I.B. 1980. Serotonininduced hyperpolarization in an identified Aplysia neuron is mediated by cyclic AMP. Proc. Natl. Acad. Sci. USA 77:5013-5017

20. Flower, R.J. 1974. Drugs which inhibit prostaglandin biosynthesis. Pharmacol. Rev. 26:33-67

21. Franson, R.C., Eisen, D., Jesse, R., Lanni, C. 1980. Inhibition of highly purified mammalian phospholipases $A_{2}$ by nonsteroidal anti-inflammatory agents. Modulation by calcium ions. Biochem. J. 186:633-636

22. Gunning, R. 1987. Increased numbers of ion channels promoted by an intracellular second messenger. Science 235:80-82

23. Hagiwara, S., Takahashi, K. 1974. The anomalous rectification and cation selectivity of the membrane of starfish egg cell. J. Membrane Biol. 18:61-80

24. Hong, S.L. 1988. THe release of arachidonic acid from cellular lipids. Prog. Allergy 44:99-139

25. Hong, S.L., Levine, L. 1976. Inhibition of arachidonic acid release from cells as the biochemical action of anti-inflammatory corticosteroids. Proc. Natl. Acad. Sci. USA 73:17301734

26. Irvine, R.F. 1982. How is the level of free arachidonic acid controlled in mammalian cells? Biochem. $J$. 204:3-16

27. Judd, A.M., Koike, K., MacLeod, R.M. 1985. GRF increases release of growth hormone and arachidonate from anterior pituitary cells. Am. J. Physiol. 248:E438-E442

28. Kiesel, L., Przylipiak, A., Emig, E., Rabe, T., Runnebaum, B. 1987. Stimulation of gonadotropin release by arachidonic acid and its lipoxygenase metabolites in superfused pituitary cells. Life Sci. 40:847-851

29. Kiesel, L., Przylipiak, A., Rabe, T., Przylipiak, M., Runnebaum B. 1987. Arachidonic acid and its lipoxygenase metabolites stimulate prolactin release in superfused pituitary cells. Hum. Reprod. 2:281-285

30. Kim, D., Clapham, D.E. 1989. Potassium channels in cardiac cells activated by arachidonic acid and phospholipids. Science 244: 1174-1176 
31. Kim, D., Lewis, D.L., Graziadei, L., Neer, E.J., Bar-Sagi, D., Clapham, D. 1989. G-protein bg-subunits activate the muscarinic $\mathrm{K}^{+}$-channel via phospholipase $\mathrm{A}_{2}$. Nature (London) 337:557-560

32. Knepel, W., Schofl, C., Gotz, D.M. 1988. Arachidonic acid elevates cytosolic free calcium concentration in rat anterior pituitary cells. Naunyn. Schmiedebergs Arch. Pharmacol. 338:303-309

33. Kramer, R.H., Levitan, I.B. 1988. Calcium-dependent inactivation of a potassium current in the Aplysia neuron R15. $J$. Neurosci. 8:1796-1803

34. Kramer, R.M., Checani, G.C., Deykin, A., Pritzker, C.R., Deykin, D. 1986. Solubilization and properties of $\mathrm{Ca}^{2+}$-dependent human platelet phospholipase $\mathrm{A}_{2}$. Biochim. Biophys. Acta 878:394-403

35. Kroner, E.E., Peskar, B.A., Fischer, H., Feber, E. 1981. Control of arachidonic acid accumulation in bone marrowderived macrophages by acyltransferases. J. Biol. Chem. 256:3690-3697

36. Kurachi, Y., Ito, H., Sugimoto, T., Shimizu, T., Miki, I., Ui, M. 1989. Arachidonic acid metabolites as intracellular modulators of the $\mathrm{G}$ protein-gated cardiac $\mathrm{K}^{+}$channel. $\mathrm{Na}$ ture (London) 337:555-557

37. Lagarde, M. 1988. Metabolism of fatty acids by platelets and the functions of various metabolites in mediating platelet function. Prog. Lipid Res. 27:135-152

38. Leech, C.A., Stanfield, P.R. 1981. Inward rectification in frog skeletal muscle fibres and its dependence on membrane potential and external potassium. J. Physiol. (London) 319:295-309

39. Levitan, E.S., Kramer, R.H., Levitan, I.B. 1987. Augmentation of bursting pacemaker activity by egg-laying hormone in Aplysia neuron R15 is mediated by a cyclic AMP-dependent increase in $\mathrm{Ca}^{2+}$ and $\mathrm{K}^{+}$currents. Proc. Natl. Acad. Sci. USA 84:6307-6311

40. Luini, A.G., Axelrod, J. 1985. Inhibitors of the cytochrome P-450 enzymes block the secretagogue-induced release of corticotropin in mouse pituitary tumor cells. Proc. Natl. Acad. Sci. USA 82:1012-1014

41. McGee, R., Jr., Sansom, M.S.P., Usherwood, P.N.R. 1988. Characterization of a delayed rectifier $\mathrm{K}^{+}$channel in NG10815 neuroblastoma $x$ glioma cells: Gating kinetics and the effects of enrichment of membrane phospholipids with arachidonic acid. J. Membrane Biol. 102:21-34

42. Metz, S.A., Draznin, B., Sussman, K.E., Leitner, J.W. 1987. Unmasking of arachidonate-induced insulin release by removal of extracellular calcium. Arachidonic acid mobilizes cellular calcium in rat islets of Langerhans. Biochem. Biophys. Res. Commun. 142:251-258

43. Miyake, A., Nishizaki, T., Ikegami, H., Koike, K., Hirota, K., Tanizawa, O. 1988. Possible involvement of lipoxygenase pathway of arachidonate acid in rat pituitary hormone release in vitro. $J$. Endocrinol. Invest. 11:805-808

44. Neufeld, E.J., Bross, T.E., Majerus, P.W. 1984. A mutant $\mathrm{HSDM}_{1} \mathrm{C}_{1}$ fibrosarcoma line selected for defective eicosanoid precursor uptake lacks arachidonate-specific acyl-CoA synthetase. J. Biol. Chem. 259:1986-1992

45. Nishizaki, T., Ikegami, H., Tasaka, K., Hirota, K., Miyake, A., Tanizawa, O. 1989. Mechanism of release of beta-endorphin from rat pituitary cells. Role of lipoxygenase products of arachidonic acid. Neuroendocrinology 49:483-488

46. Ordway, R.W., Walsh, J.J., Singer, J.J. 1989. Arachidonic acid and other fatty acids directly activate potassium channels in smooth muscle cells. Science 244:1176-1179

47. Piomelli, D., Shapiro, E., Feinmark, S.J., Schwartz, J.H. 1987. Metabolites of arachidonic acid in the nervous system of Aplysia: Possible mediators of synaptic modulation. $J$. Neurosci. 7:3675-3686

48. Piomelli, D., Volterra, A., Dale, N., Siegelbaum, S.A., Kandel, E.R., Schwartz, J.H., Belardetti, F. 1987. Lipoxygenase metabolites of arachidonic acid as second messengers for presynaptic inhibition of Aplysia sensory cells. Nature (London) 328:38-43

49. Rittenhouse, S.S. 1980. Indomethacin-induced accumulation of diglyceride in activated human platelets. The role of diglyceride lipase. J. Biol. Chem. 255:2259-2262

50. Rittenhouse-Simmons, S. 1981. Differential activation of platelet phospholipases by thrombin and ionophore A23187. J. Biol. Chem. 256:4153-4155

51. Roberts, M.F., Deems, R.A., Mincey, T.C., Dennis, E.A. 1977. Chemical modification of the histidine residue in phospholipase $\mathrm{A}_{2}$ (Naja naja naja). J. Biol. Chem. 252:2405-2411

52. Roman, I., Gmaj, P., Nowicka, C., Angielski, S. 1979. Regulation of $\mathrm{Ca}^{2+}$ efflux from kidney and liver mitochondria by unsaturated fatty acids and $\mathrm{Na}^{+}$ions. Eur. J. Biochem. 102:615-623

53. Setty, B.N., Stuart, M.J., Walenga, R.W. 1985. Formation of 11-HETE and 15-HETE in human umbilical arteries is catalyzed by cyclooxygenase. Biochim. Biophys. Acta 833:484-494

54. Shuster, M.J., Camardo, J.S., Siegelbaum, S.A., Kandel, E.R. 1985. Cyclic AMP-dependent protein kinase closes the serotonin-sensitive $\mathrm{K}^{+}$channels of Aplysia sensory neurones in cell-free patches. Nature (London) 313:392-395

55. Siegel, M.I., McConnell, R.T., Porter, N.A., Selph, J.L., Truax, J.F., Vinegar, R., Cuatrecasas, P. 1980. Aspirin-like drugs inhibit arachidonic acid metablism via lipoxygenase and cyclooxygenase in rat neutrophils from carrageenan pleural exudates. Biochem. Biophys. Res. Commun. 92:688695

56. Siegelbaum, S.A., Camardo, J.S., Kandel, E.R. 1982. Serotonin and cyclic AMP close single $\mathrm{K}^{+}$channels in Aplysia sensory neurons. Nature (London) 299:413-417

57. Sircar, J.C., Schwender, C.F., Johnson, E.A. 1983. Soybean lipoxygenase inhibition by nonsteroidal antiinflammatory drugs. Prostaglandins 25:393-396

58. Synder, G.D., Yadagiri, P., Falck, J.R. 1989. Effect of epoxyeicosatrienoic acids on growth hormone release from somatotrophs. Am. J. Physiol. 256:E221-E226

59. Spector, A.A., Yorek, M.A. 1985. Membrane lipid composition and cellular function. J. Lipid Res. 26:1015-1035

60. Turk, J., Wolf, B.A., McDaniel, M.L. 1987. The role of phospholipid-derived mediators including arachidonic acid, its metabolites, and inositol-trisphosphate and of intracellular $\mathrm{Ca}^{2+}$ in glucose-induced insulin secretion by pancreatic islets. Prog. Lipid Res. 26:125-181

61. Volwerk, J.J., Pieterson, W.A., de Haas, G.H. 1974. Histidine at the active site of phospholipase $\mathrm{A}_{2}$. Biochemistry 13:1446-1454

62. Wolf, B.A., Turk, J., Sherman, W.R., McDaniel, M.L. 1986. Intracellular $\mathrm{Ca}^{2+}$ mobilization by arachidonic acid. Comparison with myo-inositol 1,4,5-trisphosphate in isolated pancreatic islets. J. Biol. Chem. 261:3501-3511

63. Yamamoto, S. 1989. Mammalian lipoxygenases: Molecular and catalytic properties. Prostaglandins Leukot. Essent. Fatty Acids 35:219-229

64. Zeitler, P., Murphy, E., Handwerger, S. 1986. Arachidonic acid stimulates ${ }^{45}$ calcium efflux and hPL release in isolated trophoblast cells. Life Sci. 38:90-107

Received 27 October 1989 